This is the peer reviewed version of the following article: Boyd, K. A., Briggs, A. H., Bauld, L., Sinclair, L., and Tappin, D. (2016) Are financial incentives cost-effective to support smoking cessation during pregnancy? Addiction, 111: 360-370. doi:10.1111/add.13160, which has been published in final form at http://dx.doi.org/10.1111/add.13160. This article may be used for non-commercial purposes in accordance With Wiley Terms and Conditions for self-archiving. 


\title{
Title: Are financial incentives cost-effective to support smoking cessation during pregnancy?
}

\author{
AUTHORS \\ Kathleen A, Boyd ${ }^{1 *}$, Andrew H Briggs ${ }^{1}$, Linda Bauld ${ }^{2}$, Lesley Sinclair ${ }^{2}$ \& David Tappin ${ }^{3}$
}

\section{AUTHOR AFFILIATIONS}

1: Health Economics \& Health Technology Assessment, University of Glasgow, Glasgow, UK

2: Institute for Social Marketing, University of Stirling and UK Centre for Tobacco and Alcohol Studies, Stirling, UK

3: Paediatric Epidemiology and Community Health Unit, University of Glasgow, Glasgow, UK

*Corresponding author details:

Kathleen Anne Boyd

Health Economics \& Health Technology Assessment

University of Glasgow

1 Lilybank Gardens

Glasgow

G12 8RZ

Kathleen.boyd@glasgow.ac.uk

\section{DECLARATION OF INTERESTS}

The primary funder was the Chief Scientist Office, Scottish Government. Two additional main funders were the Glasgow Centre for Population Health and the Education and Research Endowment Fund of the Director of Public Health Greater Glasgow and Clyde Health Board. Additional funders were the Yorkhill Children's Charity and the Royal Samaritan Endowment Fund. The funders had no role in writing the manuscript or the decision to submit it for publication. No payment from a pharmaceutical or any other company has been paid to write this article. The authors report no competing interests.

Running Heading: Cost-effectiveness of financial incentives

Word count: 3470

Keywords: smoking cessation, pregnancy, financial incentives, cost-effectiveness 


\section{ABSTRACT}

Aims: To investigate the cost-effectiveness of up to $£ 400$ worth of financial incentives for smoking cessation in pregnancy as an adjunct to routine healthcare.Design: Cost-effectiveness analysis based on a phase II RCT and a cost-utility analysis using a lifetime Markov model. Setting: The RCT was undertaken in Glasgow, Scotland. The economic analysis is undertaken from the UK NHS perspective. Participants: 612 pregnant women randomised to receive usual cessation support +/financial incentives of up to $£ 400$ vouchers ( $\$ 609$ USD), contingent on smoking cessation.

Measurements: Comparison of usual support and incentive interventions in terms of cotinine validate quitters, Quality Adjusted Life Years (QALYs)and direct costs to the NHS. Findings: The incremental cost per quitter at 34-38 weeks pregnant was $f 1127(\$ 1716)$. This is similar to the standard look-up value derived from Stapleton \& Wests published ICER tables (72), £1390 per quitter, by looking-up the CPIT trial incremental cost ( $(157)$ and incremental 6 month quit outcome (0.14). The lifetime model resulted in an incremental cost of $£ 17(95 \% \mathrm{Cl}:-£ 93, £ 107)$ and a gain of 0.04 QALYs (95\% Cl: $-0.058,0.145$ ), giving an ICER of $£ 482 / Q A L Y(\$ 734 / Q A L Y)$. Probabilistic sensitivity analysis indicates uncertainty in these results, particularly regarding relapse after birth. The expected value of perfect information was $£ 30$ million (at a willingness to pay of $£ 30,000 / Q A L Y$ ), so given current uncertainty, additional research is potentially worthwhile. Condusion: Financial incentives for smoking cessation in pregnancy are highly cost-effective, with an incremental cost per QALY of $£ 482$, which is well below recommended decision thresholds. 


\section{INTRODUCTION}

Smoking during pregnancy is the leading preventable cause of morbidity and death amongst women and their babies $(1 ; 2)$, costing between $£ 20$ - $£ 87$ million per annum in the UK (3), and over $\$ 367$ million (4) (f241million ${ }^{1}$ ) in the USA. Smoking in pregnancy accounts for up to $30 \%$ of lowbirth weight babies and up to $14 \%$ of pre-term deliveries per annum and is associated with increased risks for ectopic pregnancy, premature rupture of membranes, still birth, low birth weight, and congenital anomalies such as cleft lip (6).

Despite these risks, 10 to $20 \%$ of pregnant women in Europe continue to smoke during pregnancy (7). In Scotland $18 \%$ of pregnant women smoke(8), and only $20 \%$ of them manage to quit during their pregnancy (9). A range of effective cessation services exist to support pregnant smokers $(10 ; 11)$, however, engagement with these services is poor as are successful quit attempts $(9 ; 12)$. Financial incentives have been proposed as a valuable addition to the behaviour change toolkit $(13 ; 14)$, with a wide body of experimental evidence supporting their success in abstinence from a range of addictive substances (15-19), including nicotine (20;21). In 2010 NICE reported there is little evidence to support use of financial incentives in a routine smoking cessation setting (11),while a Cochrane review (22) found financial incentives to be the 'single most effective intervention' for smoking cessation during pregnancy, based on four small trials conducted in the USA. Since then further trials have been published in support of financial incentives $(23 ; 24)(20 ; 25-27)$. While the efficacy evidence on financial incentives is growing, as yet there has been little economic analysis of their value in addition to existing public health services, and no cost-effectiveness analyses on their value in smoking cessation during pregnancy. The healthcare system in the UK is a publicly funded National Health Service (NHS), primarily funded through taxes providing comprehensive healthcare to all UK residents; most of which is free at the point of use. A collectively financed healthcare system such as the NHS cannot afford to fund every new clinical and public health intervention, and

\footnotetext{
${ }^{1} 1 \mathrm{USD}=0.6566 \mathrm{GBP}$, www.xe.com, $9^{\text {th }}$ February 2015
} 
therefore choices need to be made about funding allocation $(28 ; 29)$, aided by the recommended UK cost-effectiveness threshold of $f 20,000 / Q A L Y(30 ;)$. Indeed, many countries now require economic evidence prior to reimbursement (31). If financial incentives to aid smoking cessation are to be considered as an option in the UK and other high income countries, then cost-effectiveness analyses are integral to policy-making considerations. The current guidance for smoking cessation in pregnancy highlights the need for economic evidence on financial incentives for pregnant smokers (11). Therefore, this paper reports on an economic evaluation undertaken as part of a phase II randomised controlled trial (ISRCTN 87508788) (32;33) of 612 pregnant women in Glasgow, Scotland; to assess the cost-effectiveness of the offer of up to $£ 400$ of shopping vouchers in addition to routine care to help pregnant smokers quit. To our knowledge this is the first cost-effectiveness analysis of financial incentives for smoking cessation in pregnant women.

\section{METHODS}

This economic evaluation was undertaken alongside the Cessation in Pregnancy Incentives Trial (CPIT) (ISRCTN 87508788); which was a large single centre, single blinded, randomised, controlled parallel group trial, undertaken in Glasgow, Scotland. The trial recruited 612 (609 after three patients withdrew consent post randomisation) self-reported smokers who had a carbon monoxide (CO) reading of at least 7ppm at maternity booking, were aged 16 years and over, less than 24 weeks pregnant and resident in NHS Greater Glasgow and Clyde (GGC), following the published CPIT trial protocol (32). The control arm ( $n=303)$ received routine care consisting of routine referral to the NHS GGC Stop Smoking Services (SSS) which offer specialist pregnancy cessation advice in a one hour face-to-face appointment, followed by four weekly telephone support calls and 'free to the user' Nicotine Replacement Therapy (NRT) via local pharmacies for 10 weeks. The intervention arm $(n=306)$ received routine care, as described above, with the addition of up to $f 400$ vouchers (Love2shop) for engaging with the SSS ( $£ 50$ for attending the first face-to-face appointment and setting a quit date) and for quitting during pregnancy ( $\mathrm{f50}$ for achieving a 4-week $\mathrm{CO}$ validated quit, 
£100 for achieving a 12 weeks CO validated quit; and $£ 200$ for a CO validated quit at $34-38$ weeks pregnancy). Further details of the intervention, level and contingency of the incentives, randomisation, methods and outcomes for the trial are reported elsewhere $(33 ; 34)$.

The cost-effectiveness analysis was undertaken from the UK NHS perspective for cost year 2013, adhering to good practice guidelines $(30 ; 35)$. The analysis was undertaken in two parts: a within-trial analysis which utilised data on resource use and quit outcomes to report the incremental cost per late pregnancy quitter; followed by a lifetime analysis which adapted a previously published probabilistic decision analytic model $(36 ; 37)$ to assess the incremental cost per quality adjusted life year (QALY) gained. The analyses are described below, with further details provided in the supplementary report.

\section{Within trial analysis}

The primary effectiveness endpoint for the trial was the number of cotinine validated quitters at 3438 weeks pregnancy. The analysis used an intention-to-treat approach and all clients who were lost to follow-up were considered to have relapsed (33).

The direct healthcare costs for each arm of the trial are attributed to three areas: cessation support (face-to-face and telephone), NRT and financial incentives (Table 1). Unit cost information (Table 2) was combined with the trial resource use data and the mean cost per client in each arm was estimated (35). Patient level data on resource use included: duration of first contact (face-to-face support and/or first phone contact); number and duration of support calls post quit-date; number of clients accepting a four week supply of NRT at week 1 , and week 5; and in the intervention arm, the number of clients receiving financial incentives at the pre-specified time points. Administration costs such as postage and packaging for vouchers (sent via special delivery) were induded. Unit cost information was taken from routine sources such as the British National Formulary (38), the Personal Social Services Research Unit (39) and from the trial sources (value of the vouchers, postage and 
packaging charges). Costs are in UK pounds sterling for price year 2012/13. The basecase analysis does not incorporate additional research and start-up costs.

\section{INSERT TABLES 1 \& 2 NEAR HERE}

\section{Lifetime analysis}

A health economic model we previously developed $(36 ; 37)$ was adapted to incorporate the trial information, capturing the short and longer-term costs and health gains of cessation for the mother ${ }^{2}$. The model uses a Markov design to simulate the lifetime likelihood and impact of cessation, expressing the long-term health benefits of quitting smoking in terms of QALYs and the potential long-term reduction in costs to the health service of cessation. The model accounts for any relapse to smoking post-trial; in the six month period following birth, and for up to eight years postquit (which will have cost and life expectancy impacts in the long term). Post-birth hospitalisation costs for premature and low birth weight babies were included, and long-term cost of treating smoking related diseases was incorporated in a scenario analysis.

\section{INSERT FIGURE 1 NEAR HERE}

Figure 1 depicts the Markov model, which simulates the options for a cohort of pregnant smokers undertaking a quit attempt. The model consists of four main Markov states that a smoker can move to once they undertake a quit attempt: Ex-smoker, Smoker (relapsed), Non Smoking Related Death and Smoking Related Death. After a quit attempt, a woman will either be successful and become an ex-smoker, or relapse and remain a smoker. The direction of the arrows indicate possible transitions between the states. For example, ex-smokers who were successful in the quit attempt can still relapse later in life to become smokers again. It is assumed however that no further quit attempts are undertaken, so there is no transition from the smoker relapsed state to the smoker quit attempt or ex-smoker states. Ex-smokers can remain an ex-smoker, relapse to become a smoker again, die

\footnotetext{
${ }^{2}$ As the phase II CPIT trial found no difference in low birth weight or premature births between study arms (33), the lifetime economic modelling was undertaken only for the mothers.
} 
from non-smoking related causes or die from smoking related causes. Clients in the smoking relapse state remain here until they die from either a smoking or non-smoking related cause.

The model begins with a cohort of 1000 pregnant smokers, with a mean age of 28 years (average age from the trial) and runs in annual cycles until the entire cohort has died. The model is run for the routine care arm and for the financial incentives arm over the patient lifetime to calculate the mean cost, life expectancy and QALYs for each cohort. The first year of the model includes the arm specific trial costs and outcomes (up to 38 weeks pregnancy), followed by a six month post-trial period to allow for post-birth hospital costs for low birth weight babies and possible smoking relapse in mothers. Table 3 details the model input parameters and their sources, including standard errors and the distribution used in the probabilistic analysis. Costs and outcomes incurred beyond the first year were discounted at $3.5 \%$ as per recommended guidelines (24). Further details of the model, parameters, probabilistic analysis and assumptions are provided in the supplementary report.

\section{INSERT TABLE 3 NEAR HERE}

\section{Sensitivity analyses}

The model was analysed probabilistically $(30 ; 40)$ using a 1000 iteration Monte Carlo simulation to characterise uncertainty in the input parameters, and estimate confidence limits around the cost and effectiveness outcomes. Table 3 details the standard errors and distributions for the probabilistic analysis. An expected value of perfect information (EVPI) analysis (41;42) was carried out assuming an eligible population of 31,330 pregnant smokers in the UK per annum who would be referred to specialist smoking cessation services (9) over a consenatively assumed intervention lifetime of five years, discounted at $3.5 \%$.

The model was re-run under six alternative scenario analyses to explore the impact of varying some of the assumptions using (1) the self-reported 6- month postnatal relapse rates ( 12 months post quit)followed-up post trial , (2) a worst case assumption on postnatal relapse ( $80 \%$ for the Incentives arm), (3) incorporating a cost for future smoking related disease, (4) no discounting, (5) adjusting the 
analysis to account for gaming that was evidenced in the trial), (6) the trial self-reported quit rates at 34-38weeks as opposed to cotinine validated quit rates.

Finally, the amount of incentive and the corresponding impact on size of effect was considered in sensitivity analysis, given the growing evidence that substantially increasing incentive amount can impact on effect size from both the broader drug abstinence and smoking cessation fields (25)(43)(44). Scenarios $7 \& 8$ re-calculate cost-effectiveness using: (7) double the original incentive amount - a maximum of $£ 800$ vouchers (daily equivalent $£ 4$ ), (8) a maximum of $£ 1800$ vouchers (daily equivalent $\mathrm{f} 10$ ). Further information regarding the sensitivity analyses and evidence base are detailed in the supplementary report.

\section{RESULTS}

Table 4A and Figure 2 detail the base case outcomes.

\section{INSERT TABLE 4 NEAR HERE}

The within-trial analysis gave an incremental cost per late pregnancy quitter of $£ 1127$ compared to routine care. The lifetime model resulted in an incremental cost of $£ 17(95 \% \mathrm{Cl}:-£ 93, £ 107)\left(\$ 26^{3}\right)$ and a gain of 0.04 QALYs ( $95 \% \mathrm{Cl}:-0.058,0.145)$, giving an ICER of $£ 482 / Q A L Y(\$ 734 / Q A L Y)$. These results are highly cost-effective and similar to cost-effectiveness ratios found for a range of smoking cessation interventions $(45 ; 46)(72)$. Figure 2 shows the distribution of incremental cost and QALY outcomes from the probabilistic analysis on a cost-effectiveness plane. The majority of values fall in the north eastern quadrant, with an ICER of $£ 482 /$ QALY, well below the UK threshold of $£ 20,000 / Q A L Y(30)$. However, uncertainty is present- primarily due to relapse rates post trialwhich is demonstrated in Figure 2 where outcomes pass through the origin into all four quadrants.

INSERT FIGURE 2 NEAR HERE

\footnotetext{
${ }^{3} 1 \mathrm{USD}=0.6566 \mathrm{GBP}$, www.xe.com, $9^{\text {th }}$ February 2015
} 
The cost-effectiveness acceptability of the Incentives in comparison to the Control was calculated over a range of willingness to pay thresholds. At a willingness to pay of $£ 20,000$ to $£ 30,000 / Q A L Y$, Incentives had a $72 \%$ likelihood of being cost-effective compared to the Control. The probability of cost-effectiveness is detailed in Table 4B for the basecase and eight al ternative scenario analyses. Table $4 \mathrm{~B}$ shows the incentives arm is a highly cost-effective option over a range of alternative model assumptions. Only in the extreme worst case scenario 2 (assuming $80 \%$ relapse for Incentives, 30\% relapse for Control post trial) was the control arm the optimal option, with a probability of $70 \%$. Increasing the value of financial incentives offered is likely to be a cost-effective strategy as demonstrated in scenarios $7 \&$ 8; however ICER values increase substantially compared to baseline, due to diminishing returns on the level of effect. The EVPI analysis (figure 3) indicated that given current uncertainty, the value of further information is f30million. Therefore additional research to improve evidence on quit rates and relapse rates post birth and post incentive is likely to be worthwhile.

\section{Discussion}

This economic evaluation has shown that financial incentives are highly likely to be cost-effective for pregnant smokers in encouraging engagement and successful cessation during pregnancy with existing stop smoking services. Financial incentives in addition to routine care for pregnant women were found to be cost-effective at $£ 482 / \mathrm{QALY}$ (\$734/QALY) which is well below recommended costeffectiveness thresholds in high income countries $(30 ; 49 ; 50)$. This is comparable to and in some cases lower than ICERs reported for more general smoking cessation interventions $(45 ; 46 ; 51 ; 52)$, particularly those for pregnancy (53-55) .

The incremental cost per quitter outcomes from our analysis correspond with val ues from the standardised ICER tables for smoking cessation studies endorsed by Stapleton \& West to promote consistency and comparability between smoking cessation studies (72). Looking-up the CPIT trial incremental cost (£157) and incremental 6 month quit outcome (0.14) in their published tables (72), 
predicts an approximate ICER value of $£ 1390$ per quitter (72), a close similarity to our ICER of $£ 1127$ per 34-38 week CO validated quitter.

Considering the wider evidence base forfinancial incentives supporting abstinence from a range of different abused drugs $(16 ; 43)$ and for heal thy behaviours in general $(47)$ the positive findings from the CPIT Trial (33) are unsurprising (48), and this paper adds additional evidence regarding the costeffectiveness to support implementation in practice. . Following a NICE guidelines report (19) which recommended implementation of incentives for community substance abuse treatment centres in the UK; this paper further supports the cost-effective case for implementation. The basecase results for the economic analysis are highly encouraging; however, they are subject to uncertainty regarding post birth relapse, once the incentive has stopped. The uncertainty intervals around the mean cost and QALY outcomes in Table 4A, and Figure 2 demonstrate the extent of this uncertainty. . The trial did not incorporate follow-up beyond birth and only self-reported quit rates at 6 months postpartum were available. These relapse rates were encouraging:33\% relapse for Incentives and 54\% in the Control respectively(32), but without $\mathrm{CO}$ validation they are potentially biased, particularly for the Incentives arm where women may feel obliged to report a sustained quit post-trial. Therefore, literature on CO validated quits post-partum was consulted $(20 ; 64)(56)(26)$, and a conservative approach adopted, assuming post-birth relapse rates which favoured the Control arm(60\% relapse for Incentives, 30\% relapse in the Control, as detailed in Table 3) (26)(64). Scenario 1 of the sensitivity analyses reports outcomes when we adopt the post-trial self-reported rates, giving an improved ICER of $f 164 /$ QALY (\$250/QALY) and a 99\% probability that Incentives are the costeffective option. In future trials, CO-validated evidence post-birth and post incentive would be beneficial and strengthen the evidence base. A future trial which measured longer-term relapse rates could also explore the cost-effectiveness of financial incentive for relapse prevention post birth, given the demonstrated success of financial incentives in the short term. 
arms (34)(28)

A possible unintended consequence of financial incentives is the possibility of 'gaming'; whereby women could be untruthful about their smoking status, especially at the time of the primary outcome assessment where $50 \%$ of the incentive is offered. The CPIT and economic analysis tested for this type of 'gaming' (33) and found approximately $20 \%$ of women were untruthful about their smoking status, in both arms. This is higher than a recent single arm study on financial incentives in England, which found only $4 \%$ of participants gamed to gain cessation vouchers (26). Scenario 5 of our sensitivity analysis (Table 4B) adjusted for gaming (adjusting quit rates to exclude gamers, but keeping the costs incurred by them) and found incentives remained cost-effective, but with an increased ICER of $£ 1443 /$ QALY (\$2198/QALY). This ICER remains well below the thresholds in high income countries $(24 ; 39 ; 40)$, so even accounting for gaming, would be considered cost-effective.

Many high income countries offer a variety of specialist cessation interventions during pregnancy $(1 ; 2 ; 6 ; 49 ; 50)$ yet in the UK only $25 \%$ of pregnant women make a quit attempt, and only $8 \%$ have been found to (via self-report) quit(58). The CPIT trial found a significant increase in quit when offered Incentives(22.5\%) than Control (8.6\%), a cessation improvement that is larger than that seen in most behavioural, (59) or pharmaceutical (60) pregnancy cessation trials. Previous systematic reviews of varied intervention strategies (59) highlight that current recommendations to help smokers quit during pregnancy (11) are not very effective. There is a growing evidence base showing financial incentives to have positive effects on health behaviours (11;13)(15-19), particularly in the smoking cessation arena $(20,21)$. Likis et al. (61) recently reported that out of a range of interventions for smoking cessation during pregnancy, financial incentives demonstrated the strongest effect. Despite this evidence base, few studies have considered the cost-effectiveness of financial incentives, and none have assessed this for smoking cessation during pregnancy. If financial 
incentives to aid smoking cessation are to be considered as an option in high income countries, then economic analyses are essential to policy-making considerations.

\section{Policy Implications}

Identifying pregnant women who smoke, engaging with them and supporting them to quit smoking during pregnancy is a key international tobacco policy priority $(11 ; 62)$ and this study provides evidence on the cost-effectiveness of financial incentives as a means to achieving cessation during pregnancy.

Godfrey et al. (3) found the cost of smoking during pregnancy is $f 8$ - $f 64$ million per annum (\$367million (4) in the USA). They estimate that low cost cessation interventions (costing between f13 and $f 37$ per pregnant smoker) could yield positive cost savings, but recommend further research on enhanced investment in smoking cessation interventions. Our sensitivity analysis (scenarios $7 \& 8$ ) show that enhanced incentives offering up to $f 800$ and $£ 1800$ per quitter could potentially be cost-effective, while the base case analysis on the CPIT trial (33) provides evidence that financial incentives up to $£ 400$ in addition to routine care are a highly cost-effective way to encourage quit attempts and achieve cessation in pregnancy.

This research paper provides economic evidence based on a phase II RCT to support the use of financial incentives in addition to routine smoking cessation services for pregnant women. Our findings address the gap in cost-effectiveness evidence (10) (11), showing financial incentives are a potentially cost-effective way to help women who smoke to engage with cessation services, and quit when they are pregnant.

\section{Strengths and weaknesses}


The key strengths of this study are the RCT design and cost-effectiveness analysis. The resource use and outcome data was informed from an RCT, and to our knowledge this is the first costeffectiveness analysis of financial incentives for pregnant smokers.

Key limitations are in the exploratory (phase II) nature of the trial, in that it was limited to one geographical location in Glasgow, Scotland. This sample is potentially representative of large city populations; however, routine cessation services for pregnant women vary throughout the UK.. Another limitation relates to the uncertainty of the data on relapse post birth (once financial incentives have stopped). The self-report postnatal data following the CPIT trial was encouraging, however, it could be subject to intervention group bias. If these findings remained the same in a cotinine validated follow-up, then the QALYs difference between the trial arms is likely to be real. However, given current uncertainty, the expected value of perfect information analysis showed that it is worthwhile to undertake further research.

This work strengthens the evidence base on potential cost-effectiveness of financial incentives and thus is extremely valuable for policy makers, both in the UK and in other high income countries in Europe and the USA.

\section{CONCLUSION}

Existing interventions for pregnant smokers are not highly effective; however, this study provides substantial evidence on the cost-effectiveness of a financial incentives intervention to add to existing cessation support. This study shows financial incentives to be highly cost-effective with an incremental cost-effectiveness ratio (ICER) of $£ 482 /$ QALY (\$734/QALY) which is well below recommended thresholds. 


\section{WHAT THIS PAPER ADDS}

- This is the first cost-effectiveness analysis of financial incentives for smoking cessation in pregnant women

- This study shows that financial incentives are highly likely to be cost-effective

- CO validated evidence regarding sustained quit once the incentive has ended and relapse post birth is needed to strengthen the evidence base.

\section{ACKNOWLEDGEMENTS}

We would also like to acknowledge the other members of the Cessation in Pregnancy Incentives Trial (CPIT) team. Brenda Friel, M.P.H., Alan Cameron, Honorary Professor, Obstetrics and Gynaecology, School of Medicine, University of Glasgow. Liz Grant, Lead Public Health Pharmacist (Health Improvement), Margaret McFadden, Research Nurse, Anne Benson, Project Assistant, NHS Greater Glasgow and Clyde. Sue Stevenson, Research Nurse, University of Glasgow. Carol Anne Greenan, Research Administrator, University of Stirling. Caroline Haig, Trainee Biostatistician, John McHugh, Clinical Database Manager, Robertson Centre for Biostatistics and Glasgow Clinical Trials Unit. 
Reference List

(1) Lowry C, Scammell K. Smoking cessation in pregnancy: a call to action. =Action on Smoking and Health (ASH); Royal College of Nursing; 2013. Report No.: ISBN: 978-1-872428-92-5.

(2) World Health Organisation. WHO recommendations for the prevention and management of tobacco use and second-hand smoke exposure in pregnancy. 2013.

(3) Godfrey C, Pickett K, Parrott S, Mdege N, Eapen P. Estimating the Costs to the NHS of Smoking in Pregnancy for Pregnant Women and Infants. York: Public Health Research Consortium, University of York; 2010. Report No.: Final report.

(4) Adams E, Miller V, Ernst C, Nishimura B, Melvin C, Merritt R. Neonatal health care costs related to smoking during pregnancy. Health Economics 2002;11(3):193-206.

(5) American Lung Association. Facts \& Figures: Women and Tobacco Use. American Lung Association; 2015.

(6) World Health Organisation. WHO Report on the Global Tobacco Epidemic 2009: Implementing Smoke-Free Environments. Geneva, Switzerland; 2009.

(7) European Medicines Agency. Guideline on the Development of Medicinal Products for the Treatment of Smoking. London, UK: European Medicines Agency; 2008.

(8) Information Services Division. Births in Scottish Hospitals: year ending 31 ${ }^{\text {st }}$ March 2013. 2014.

(9) Tappin D, MacAskill S, Bauld L, Eadie D, Shipton D, Galbraith L. Smoking prevalence and smoking cessation services for pregnant women in Scotland. Substance AbuseTreatment, Prevention and Policy 2010;5(1).

(10) Bauld L, Coleman T. The effectiveness of smoking cessation interventions during pregnancy: A briefing paper. London, UK: National Institute for Health \& Clinical Excellence; 2009.

(11) National Institute for Health and Clinical Excellence. Quitting smoking in pregnancy and following childbirth. London, UK: National Institute for Health \& Clinical Excellence; 2010.

(12) Bostock Y. Searching for the solution: Women, smoking and inequalities in Europe. Health Development Agency, NHS; 2003.

(13) Volpp K, Troxel A, Pauly M, Glick H, Puig A, Asch D, et al. A randomized controlled trial of financial incentives for smoking cessation. New England Journal of Medicine 360[7], 699709. 2009.

(14) Giles E, Robalino S, McColl E, Sniehotta F, Adams J. The Effectiveness of Financial Incentives for Health Behaviour Change: Systematic Review and Meta-Analysis. PLoS ONE 2014;9(3):e90347.

(15) Higgins ST, Silverman K, Heil S. Contingency Management in Substance Abuse Treatment. New York: Guilford; 2008. 
(16) Higgins ST. Comments on Contingency Management and Conditional Cash Transfers. Health Economics 2010;19(10):1255-8.

(17) Lussier J, Heil S, Mongeon J, Badger G, Higgins ST. A meta-analysis of voucher-based reinforcement therapy for substance use disorders. Addiction 2006;101(2):192-203.

(18) Grand J, Titmuss R, Srivastava D. Incentives for Prevention. 2009. Report No.: Health england Report No. 3.

(19) Pilling S, Strang J, Gerada C. Psychosocial interventions and opioid detoxification for drug misuse: summary of NICE guidelines. British Medical Journal 2007;2007(335):203-5.

(20) Higgins ST, Washio Y, Heil S. Financial incentives for smoking cessation among pregnant and newly postpartum women. Preventive Medicine 2012;55(Supplement):S33-40.

(21) Hoddinott P, Morgan H, MacLennan G, Sewel K, Thomson G, Bauld L, et al. Public acceptability of financial incentives for smoking cessation in pregnancy and breast feeding: a survey of the British public. BMJ Open 2014;4(e005524).

(22) Lumley J, Oliver S, Chamberlain C, Oakley L. Interventions for promoting smoking cessation during pregnancy. Cochrane Database of Systematice Reviews 2009;3(CD001055).

(23) Coleman T, Cooper S, Thornton J, Grainge M, Watts K, Britton J, et al. A Randomized Trial of Nicotine-Replacement Therapy Patches in Pregnancy. New England Journal of Medicine 2012 Feb 29;366(9):808-18.

(24) Coleman T, McEwen A, Bauld L, Ferguson J, Lorgelly P, Lewis S. Protocol for the proactive or reactive telephone smoking cessation support (PORTSSS) trial. Trials 10[26], 1-12. 2009.

(25) Higgins ST, Washio Y, Lopez A, Heil S, Solomon L, Lynch M, et al. Examining two different schedules of financial incentives for smoking cessation among pregnant woment. Preventive Medicine 2014;68:51-7.

(26) Ierfino D, Mantzari E, Hirst J, Jones T, Aveyard P, Marteau T. Financial incentives for smoking cessation in pregnancy: a single-arm intervention stuidy assessing cessation and gaming. Addiction 2015;110:680-8.

(27) Tuten $\mathrm{M}$, Fitzsimmons $\mathrm{H}$, Chisolm M, Nuzzo P, Jones $\mathrm{H}$. Contingent incentives reduce cigarette smoking in pregnant, methodone-maintained women: results of an initial feasibility and efficacy randomized controlled trial. Addiction 2012;107:1868-77.

(28) Schlander M. Health Technology Assessments by the National Institute for Health Clinical Excellence: a qualitative study. New York: Springer; 2007.

(29) National Institute for Health and Care Excellence. NICE: What we do. 2014.

(30) National Institute for Health and Care Excellence. Guide to the Methods of Technology Appraisal: 2013. National Institute for Health and Clinical Excellence; 2013.

(31) Hutton J, McGarth C, Frybourg J, Tremblay M, Bramley-Harker E, Henshall C. Framework for describing and classifying decision-making systems using technology assessment to 
determine the reimbursement of health technologies (fourth hurdle systems). International Journal of Technology Assessment in Health Care 22[1], 10-18. 2006.

(32) Tappin D, Bauld L, Tannahill C, De Caestecker L, Radley A, McConnachie A, et al. The Cessation in Pregnancy Incentives Trial (CPIT): study protocol for a randomised controlled trial. Trials 2012;13:113.

(33) Tappin D, Bauld L, Boyd KA, Sinclair L, MacAskill S, McKell J, et al. Financial Incentives for Smoking cessation in Pregnancy (CPIT): Randoimised Controlled Trial. British Medical Journal 2015;350.

(34) Tappin D, Bauld L, Purves D, Boyd K, Sinclair L, MacAskill S, et al. Financial incentives for smoking cessation during pregnancy: A randomised controlled trial. The Lancet . 2014.

(35) Petrou S, Gray A. Economic evaluation alongside randomised controlled trials: design, conduct, analysis, and reporting. British Medical Journal 2011;342(1548):1069-73.

(36) Boyd KA, Briggs AH. Cost-effectiveness of pharmacy and group behavioural support smoking cessation services in Glasgow. Addiction 104, 317-325. 2009.

(37) Bauld L, Boyd KA, Briggs AH, Chesterman J, Ferguson J, Judge K, et al. One year outcomes and a cost-effectiveness analysis for smokers accessing group-based and pharmacy-led treatment services. Nicotine \& Tobacco Research 2011;13(2):135-45.

(38) British National Formulary. British National Formulary 66. 2013.

(39) Curtis L. Unit Costs of Health and Social Care 2012. University of Kent at Canterbury: PSSRU; 2012.

(40) Briggs $\mathrm{AH}$. Handling uncertainty in economic evaluations and presenting the results. In: Drummond M, McGuire A, editors. Economic Evaluation in Health Care: merging theory with practice.Oxford: Oxford University Press; 2001. p. 172-214.

(41) Fenwick E, Byford S. A guide to cost-effectiveness acceptability curves. British Journal of Psychiatry 187[106], 108. 2005.

(42) Fenwick E, Palmer S, Claxton K, Sculpher M, Abrams K, Sutton A. An iterative Bayesian approach to health technology assessment: application to a policy of preoperative optimization for patients undergoing major elective surgery. Medical Decision Making 26, 480-496. 2006.

(43) Lussier J, Heil S, Mongeon J, Badger G, Higgins ST. A meta-analysis of voucher-based reinforcement therapy for substance use disorders. Addiction 2006;101(2):192-203.

(44) Higgins ST, Bernstein I, Washio Y, Heil S, Badger G, Skelly J, et al. Effects of smoking cessation with voucher-based contingency management on birth outcomes. Addiction 2010;105:202330.

(45) Godfrey C, Parrott S, Coleman T, Pound E. The cost-effectiveness of the English smoking treatment services: evidence from practice. Addiction 2005;100(Supplement 2):70-83. 
(46) Owen L, Morgan A, Fischer A, Ellis S, Hoy A, Kelly M. The cost-effectiveness of public health interventions. Joumal of Public Health 2011;34(1):37-45.

(47) Dallat M, Hunter R, Tully M, Cairns K, Kee F. A lesson in business: cost-effectiveness analysis of a novel financial incentive intervention for increasing physical activity in the workplace. BMC Public Health 2013;13:953.

(48) Higgins ST. A larger context for considering the Tappin et al. report on financial incentives for smoking cessation in pregnant and newly postpartum women. British Medical Journal 2015;350(h134).

(49) Menon D, Stafinski T. Health Technology Assessment in Canada: 20 Years Strong? Value In Health 2009;12(Supp 2):S14-S19.

(50) Marseille E, Larson B, Kazi D, Kahn J, Rosen S. Thresholds for the cost-effectiveness of interventions: alternative approaches. Bulletin of the World Health Organization 2015;93:118-24.

(51) Hoogendoorn M, Welsing P, Rutten-van Molken MP, Hoogendoorn M, Welsing P, RuttenVan Molken MPMH. Cost-effectiveness of varenicline compared with bupropion, NRT, and nortriptyline for smoking cessation in the Netherlands. Current Medical Research \& Opinion 2008 Jan;24(1):51-61.

(52) Chen F, Madan J, Welton N, Yahaya I, Aveyard P, Bauld L, et al. Effectiveness and costeffectiveness of computer and other electronic aids for smoking cessation: a systematic review and network meta-analysis. Health Technology Assessment 2012;16(38).

(53) Cooper S, Lewis S, Thornton J, Marlow N, Watts K, Britton J, et al. The SNAP trial: a randomised placebo-controlled trial of nicotine replacement therapy in pregnancy - clinical effectiveness and safety until 2 years after delivery, with economic evaluation. Health Technology Assessment 2014;18(54).

(54) Dornelas E, Magnavita J, Beazoglou T, Fischer E, Oncken C, Lando H, et al. Efficacy and costeffectiveness of a clinic-based counseling intervention tested in an ethnically diverse sample of pregnant smokers. Patient Education \& Counselling 2006;64:342-9.

(55) Ruger JP, Emmons K. Economic Evaluations of Smoking Cessation and Relapse Prevention Programs for Pregnant Women: A Systematic Review. Value In Health 11[2], 180-190. 2008.

(56) Marteau T, Thorne J, Aveyard P, Hirst J, Sokal R. Financial incentives for smoking cessation in pregnancy: protocol for a single arm intervention study. BMC Pregnancy and Childbirth 2013;13(1):66.

(57) Batech M, Tonstad S, Job J, Chinnock R, Oshiro B, Merritt T, et al. Estimating the Impact of Smoking Cessation During Pregnancy: The San Bernardino County Experience. Journal of Community health 2013;38:838-46.

(58) Information Services Division. NHS Smoking Cessation Services (Scotland): 1st january to 31st december 2014. 2015. 
(59) Chamberlain C, O'Mara-Eves A, Oliver S, et al. Psychosocial interventions for supporting women to stop smoking in pregnancy. Cochrane Database of Systematice Reviews 2013;2013(10).

(60) Berlin I, Grange G, Jacob N, Tanguy M. Nicotine patches in pregnant smokers: randomised, placebo controlled, multicentre trial of efficacy. British Medical Journal 2014;348.

(61) Likis F, Andrews J, Fonnesbeck C, Hartmann K, Jerome R, Potter S, et al. Smoking Cessation Interventions in Pregnancy and Postpartum Care. Agency for Healthcare Research \& Quality; 2014. Report No.: Evidence Report Number 214.

(62) ASH Scotland. Smoking \& Tobacco Statistics Fact Sheet. 2014.

(63) Cahill K, Perara R. Competitions and Incentives for Smoking Cessation. Cochrane Database of Systematice Reviews 2011;(4).

(64) Donatelle R, Prows S, Champeau D, Hudson D. Randomised controlled trial using social support and financial incentives for high risk pregnant smokers: Significant Other Supporter (SOS) program. Tobacco Control 9[Supp III], 67-69. 2000.

(65) Yudkin P, Hey K, Roberts S, Welch S, Murphy M, Walton R. Abstinence from smoking eight years after participation in randomised controlled trial of nicotine patch. British Medical Journal 327, 28-29. 2003.

(66) British National Formulary. BNF 65. 2012 Mar.

(67) Information Services Division. Scottish Health Service Costs Book 2012. Information Services Division; 2012.

(68) ASH Scotland. Up in Smoke: The economic cost of tobacco in Scotland. 2010.

(69) General Register Office for Scotland. Vital Events Reference Tables 2012: Deaths - Table 5.1b age sex death rates. General Register Office for Scotland; 2013.

(70) Peto R, Lopez A, Boreham J, Thun M. Mortality from smoking in developed countries 1950 2005 (or later): Scotland. 2012.

(71) Kind P, Hardman G, Macran S. UK population Norms for EQ-5D. York: Centre for Health Economics, University of York; 1999. Report No.: Discussion Paper 172.

(72) Stapleton JA. \& West, R., A direct method and ICER tables for the estimation of the costeffectiveness of smoking cessation interventions in general populations: application to a new cytisine trial and other examples. Nicotine \& Tobacco Research 14(4), 463-71. 2012. 


\section{Tables \& Figures}

Table 1: Resource Use Information

\begin{tabular}{|c|c|c|c|c|}
\hline Resource & & & Incentives & Control \\
\hline Vouchers & & & Number* & Number* \\
\hline Vouchers postage \& packaging & & & 504 & NA \\
\hline Additional vouchers re-posted & & & 30 & NA \\
\hline 1st Incentive: 1st face to face contact $f 50$ & & & 248 & NA \\
\hline 2nd incentive: 4 wks post quit $f 50$ & & & 96 & NA \\
\hline 3rd Incentive: 12 weeks post quit $£ 100$ & & & 79 & NA \\
\hline 4th Incentive: $34-38$ wks $£ 200 \mathrm{CO}$ validated & & & 81 & NA \\
\hline Cessation Support & Duration & $\begin{array}{l}\text { std } \\
\text { error }\end{array}$ & Number* & Number* \\
\hline 1st phone contact (minutes) & 10.00 & 5.10 & 210 & 225 \\
\hline 1st face-face support (minutes) & 50.00 & 15.31 & 248 & 236 \\
\hline 1st post quit-date phone call only (minutes) & 15.00 & 7.65 & 1 & 1 \\
\hline 1st \& 2nd post quit-date phone calls & 15.00 & 7.65 & 3 & 7 \\
\hline 1 st, 2 nd \& 3 rd post quit-date phone calls & 15.00 & 7.65 & 9 & 26 \\
\hline $1 s t, 2$ nd $3 r d \& 4$ th post quit-date phone calls & 15.00 & 7.65 & 21 & 38 \\
\hline $1 \mathrm{st}, 2 \mathrm{nd}, 3 \mathrm{rd}, 4$ th $\& 5$ th post quit-date calls & 15.00 & 7.65 & 212 & 160 \\
\hline Unknown (assume mean 4.8 calls) $\dagger$ & & & 5 & 6 \\
\hline Unknown (assume no calls) $† \dagger$ & & & 55 & 68 \\
\hline Nicotine Replacement Therapy & & & Number* & Number* \\
\hline NRT 4 week prescription wk 1 & & & 158 & 155 \\
\hline NRT 4 week prescription wk 5 & & & 61 & 38 \\
\hline NRT 4 week prescription wk 10 & & & 32 & 15 \\
\hline
\end{tabular}

*Number of participants in each arm of CPIT trial receiving which resources

tattended $1^{\text {st }}$ face to face meeting - assume mean 4.8 calls

++ did not attend $1^{\text {st }}$ face to face meeting - assume zero post quit date calls

Table 2: Unit Cost Information

\begin{tabular}{lll}
\hline Cost Area & Unit Costs & Source \\
\hline Smokefree Pregnancy advisor (Band 5) cost per hour & $£ 35.00$ & Curtis, L 2013 \\
NRT: Nicorette 16hr patch (1st line) cost per week & $£ 9.97$ & BNF 2013 \\
Low Birth weight: Special Care Baby Unit cost per case & $£ 8,602.00$ & ISD, 2012 \\
Vouchers postage \& packaging & $£ 7.48$ & CPIT trial \\
Additional vouchers re-posted (postage only 2013) & $£ 7.46$ & CPIT trial \\
1st Incentive: 1st face to face contact £50 & $£ 50.00$ & CPIT trial \\
2nd incentive: 4 wks post quit £50 & $£ 50.00$ & CPIT trial \\
3rd Incentive: 12 weeks post quit f100 & $£ 100.00$ & CPIT trial \\
4th Incentive: CO validated 34-38 wks £200 & $£ 200.00$ & CPIT trial \\
\hline
\end{tabular}


Table 3: Lifetime Model parameter inputs

\begin{tabular}{|c|c|c|c|c|}
\hline Parameters & Value & std error & distribution & source \\
\hline \multicolumn{5}{|l|}{ Trial Outcomes } \\
\hline 34-38week quit Incentive (cotinine validated) & 0.225 & 0.0239 & beta & (33) \\
\hline 34-38week quit Control (cotinine validated) & 0.086 & 0.0161 & beta & (33) \\
\hline P very low \& low birth weight - quitters & 0.03 & 0.0180 & beta & (33) \\
\hline P very low \& low birth weight - smokers & 0.15 & 0.0156 & beta & (33) \\
\hline \multicolumn{5}{|l|}{ Cessation Support } \\
\hline Duration 1st phone call (mins) & 10.00 & 5.1020 & gamma & (33) \\
\hline Duration 1st face-to-face support (mins) & 50.00 & 15.3061 & gamma & (33) \\
\hline Duration post quit date phone calls (mins) & 15.00 & 7.6531 & gamma & (33) \\
\hline \multicolumn{5}{|l|}{ Relapse Rates } \\
\hline P Relapse 3 months post birth Incentive & 0.60 & 0.1800 & beta & $(20 ; 26)$ \\
\hline P Relapse 3 months post birth Control & 0.30 & 0.0600 & beta & $(64), A A$ \\
\hline Annual P Relapse yrs $1-5$ post quit & 0.05 & NA & NA & (65) \\
\hline Annual P Relapse yrs 6-8 post quit & 0.03 & NA & NA & (65) \\
\hline \multicolumn{5}{|l|}{ Unit Costs } \\
\hline NRT, 1st line (cost/week) & $£ 9.97$ & NA & NA & (66) \\
\hline Smokefree Pregnancy advisor (cost/hr) & $£ 35.00$ & NA & NA & (39) \\
\hline Incentive voucher postage \& packaging & $£ 7.48$ & NA & NA & (33) \\
\hline Incentive voucher 1 st \& 2 nd & $£ 50.00$ & NA & NA & (33) \\
\hline Incentive voucher 3rd & $£ 100.00$ & NA & NA & (33) \\
\hline Incentive voucher 4 th & $£ 200.00$ & NA & NA & (33) \\
\hline NHS cost for low \& very low birth weight ${ }^{\dagger}$ & $£ 8,602$ & $£ 1,720$ & gamma & (67) \\
\hline Cost smoking related disease - basecase & fo & £0 & NA & $A A$ \\
\hline Cost smoking related disease $+\dagger$ - scenario & $£ 32,658$ & $£ 6,532$ & gamma & (68) \\
\hline \multicolumn{5}{|l|}{ Mortality rates } \\
\hline Scottish female smoking related mortality** & & NA & $(69 ; 70)$ \\
\hline Scottish female mortality excluding smoking** & \multicolumn{2}{|c|}{ mortality tables } & NA & $(69 ; 70)$ \\
\hline \multicolumn{5}{|l|}{ Utilities } \\
\hline female smoker age $25-34$ & 0.92 & 0.0024 & beta & $(71)$ \\
\hline female smoker age $35-44$ & 0.89 & 0.0027 & beta & (71) \\
\hline female smoker age $45-54$ & 0.78 & 0.0043 & beta & (71) \\
\hline female smoker age 55-64 & 0.69 & 0.0048 & beta & (71) \\
\hline female smoker age $65-74$ & 0.75 & 0.0051 & beta & (71) \\
\hline female smoker age $75+$ & 0.67 & 0.0051 & beta & (71) \\
\hline female non smoker age $25-34$ & 0.93 & 0.0027 & beta & (71) \\
\hline female non smoker age $35-44$ & 0.92 & 0.0024 & beta & (71) \\
\hline female non smoker age $45-54$ & 0.87 & 0.0036 & beta & (71) \\
\hline female non smoker age 55-64 & 0.82 & 0.0041 & beta & (71) \\
\hline female non smoker age 65-74 & 0.78 & 0.0043 & beta & (71) \\
\hline female non smoker age $75+$ & 0.72 & 0.0045 & beta & $(30 ; 71)$ \\
\hline \multicolumn{5}{|l|}{ Discount Rate } \\
\hline outcomes \& costs (beyond yr 1 ) & 0.035 & NA & & (24) \\
\hline
\end{tabular}

$\mathrm{P}=$ probability, $\mathrm{AA}=$ Author assumption

*Scena rio analysis 1 uses self-reported 3 month relapse rates; † Mean cost Special Ca re Baby Unit, inpa tient cost per case

†† Scenario Analysis 3: mean cost $£ 32,658$ persmoking related dea th

** Life tables for Scottish Females, age adjus ted population dea th rates per 1000 
Table 4: 4A - Basecase analysis results, 4B - Scenario analyses results

\begin{tabular}{|c|c|c|c|c|c|c|c|c|}
\hline & \multirow{2}{*}{$\begin{array}{l}\text { Table 4A } \\
\text { Economic Analysis } \\
\text { Within trial } \\
\text { (incremental cost per quitter) }\end{array}$} & \multirow{2}{*}{$\begin{array}{l}\text { Arm } \\
\text { Control } \\
\text { Incentives }\end{array}$} & \multirow{2}{*}{$\begin{array}{l}\text { Mean } \\
\text { Cost } \\
\text { f85 } \\
\text { f243 }\end{array}$} & \multirow{2}{*}{$\begin{array}{l}\text { Mean } \\
\text { effect } \\
\text { quit } \\
0.09 \\
0.23 \\
\end{array}$} & \multirow{2}{*}{$\begin{array}{c}\text { Incremental } \\
\text { Cost } \\
£ 157 \\
(£ 155, £ 162) \\
\end{array}$} & \multirow{2}{*}{$\begin{array}{c}\begin{array}{c}\text { Incremental } \\
\text { effect }\end{array} \\
\text { quit } \\
0.14 \\
(0.08,0.19) \\
\end{array}$} & \multicolumn{2}{|c|}{$\begin{array}{l}\text { Incremental cost- } \\
\text { effectiveness ratio (ICER) }\end{array}$} \\
\hline & & & & & & & $£ 1,127$ & per quitter \\
\hline & $\begin{array}{l}\text { Lifetime } \\
\text { (incremental cost per QALY) }\end{array}$ & $\begin{array}{l}\text { Control } \\
\text { Incentives }\end{array}$ & $\begin{array}{l}f 1,265 \\
f 1,282\end{array}$ & $\begin{array}{l}\text { QALY } \\
19.101 \\
19.137 \\
\end{array}$ & $\begin{array}{c}17 \\
(-£ 93, £ 107)\end{array}$ & $\begin{array}{c}\text { QALY } \\
0.036 \\
(-0.058,0.145) \\
\end{array}$ & $£ 482$ & per QALY \\
\hline & $\begin{array}{l}\text { Table 4B } \\
\text { Scenario Analyses }\end{array}$ & Arm & $\begin{array}{l}\text { Mean } \\
\text { Cost }\end{array}$ & $\begin{array}{l}\text { Mean } \\
\text { QALYs }\end{array}$ & $\begin{array}{l}\text { Incremental } \\
\text { Cost }\end{array}$ & $\begin{array}{c}\text { Incremental } \\
\text { QALYs }\end{array}$ & ICER & $\begin{array}{l}\text { Prob CE } \\
£ 30 K / Q^{*}\end{array}$ \\
\hline & Base-case analysis & $\begin{array}{l}\text { Control } \\
\text { Incentives }\end{array}$ & $\begin{array}{l}£ 1,265 \\
£ 1,282\end{array}$ & $\begin{array}{l}19.10 \\
19.14 \\
\end{array}$ & $£ 17$ & 0.036 & $£ 482$ & 0.72 \\
\hline 1 & $\begin{array}{l}\text { Self-reported postnatal relapse } \\
\text { Incentives 33\%, Control } 54 \%\end{array}$ & $\begin{array}{l}\text { Control } \\
\text { Incentives }\end{array}$ & $\begin{array}{l}£ 1,245 \\
f 1,267\end{array}$ & $\begin{array}{l}19.08 \\
19.21 \\
\end{array}$ & $\begin{array}{c}£ 21 \\
(-£ 87, £ 101)\end{array}$ & $\begin{array}{c}0.13 \\
(0.018,0.228) \\
\end{array}$ & $£ 164$ & 0.99 \\
\hline 3 & $\begin{array}{l}\text { Include cost for } \\
\text { smoking related disease } \\
(£ 32,658 \text {, se } £ 6532)\end{array}$ & $\begin{array}{l}\text { Control } \\
\text { Incentives }\end{array}$ & $\begin{array}{l}£ 25,397 \\
£ 24,820\end{array}$ & $\begin{array}{l}19.10 \\
19.14\end{array}$ & $\begin{array}{c}-£ 577 \\
(-£ 2382, £ 821) \\
\end{array}$ & $\begin{array}{c}0.039 \\
(-0.05,0.15) \\
\end{array}$ & $\begin{array}{l}\text { Incentives } \\
\text { Dominates }\end{array}$ & 0.73 \\
\hline 4 & Discount rate $0 \%$ & $\begin{array}{l}\text { Control } \\
\text { Incentives }\end{array}$ & $\begin{array}{l}£ 1,254 \\
£ 1,274\end{array}$ & $\begin{array}{l}40.02 \\
40.14 \\
\end{array}$ & $\begin{array}{c}£ 20 \\
(-£ 90, £ 100) \\
\end{array}$ & $\begin{array}{c}0.117 \\
(-0.187,0.459) \\
\end{array}$ & $£ 167$ & 0.75 \\
\hline 5 & $\begin{array}{l}\text { Gaming: exclude } 20 \% \text { quitters } \\
\text { Probability } 34-38 \text { week quit: } \\
\text { Incentives } 18 \% \text {, Control } 7 \%\end{array}$ & $\begin{array}{l}\text { Control } \\
\text { Incentives }\end{array}$ & $\begin{array}{l}f 1,273 \\
£ 1,320\end{array}$ & $\begin{array}{l}19.09 \\
19.12\end{array}$ & $\begin{array}{c}£ 47 \\
(-£ 47, £ 111)\end{array}$ & $\begin{array}{c}0.033 \\
(-0.036,0.121)\end{array}$ & $£ 1,443$ & 0.74 \\
\hline 6 & $\begin{array}{l}\text { Use self reported quit rates } \\
\text { Probability quit } 34-38 \text { weeks: } \\
\text { Incentives } 39 \% \text {, Control } 21 \%\end{array}$ & $\begin{array}{l}\text { Control } \\
\text { Incentives }\end{array}$ & $\begin{array}{l}\mathrm{f1}, 137 \\
£ 1,121\end{array}$ & $\begin{array}{l}19.21 \\
19.21\end{array}$ & $\begin{array}{c}-£ 16 \\
(-£ 153, £ 86)\end{array}$ & $\begin{array}{c}0.003 \\
(-0.14,0.196)\end{array}$ & $\begin{array}{l}\text { Incentives } \\
\text { Dominates }\end{array}$ & 0.49 \\
\hline 7 & Increase incentive max $£ 800$ & Control & $f 1,256$ & 19.10 & £152 & 0.062 & f2461 & 0.64 \\
\hline
\end{tabular}




\begin{tabular}{|c|c|c|c|c|c|c|c|c|}
\hline & Prob quit $34-38$ week: 0.28 : & Incentives & $£ 1,408$ & 19.16 & $(£ 81, £ 538)$ & $(-0.03,0.184)$ & & \\
\hline \multirow[t]{2}{*}{8} & Increase incentive max $£ 1800$ & Control & $£ 1,256$ & 19.10 & $f 579$ & 0.133 & $£ 4360$ & 0.59 \\
\hline & Prob quit 34-38 week: 0.43: & Incentives & $£ 1,835$ & 19.23 & $(£ 236, £ 982)$ & $(-0.04,0.362)$ & & \\
\hline
\end{tabular}

* probability that Incentives Arm is cost-effective at a threshold of $£ 30,000 / \mathrm{QALY}$ 


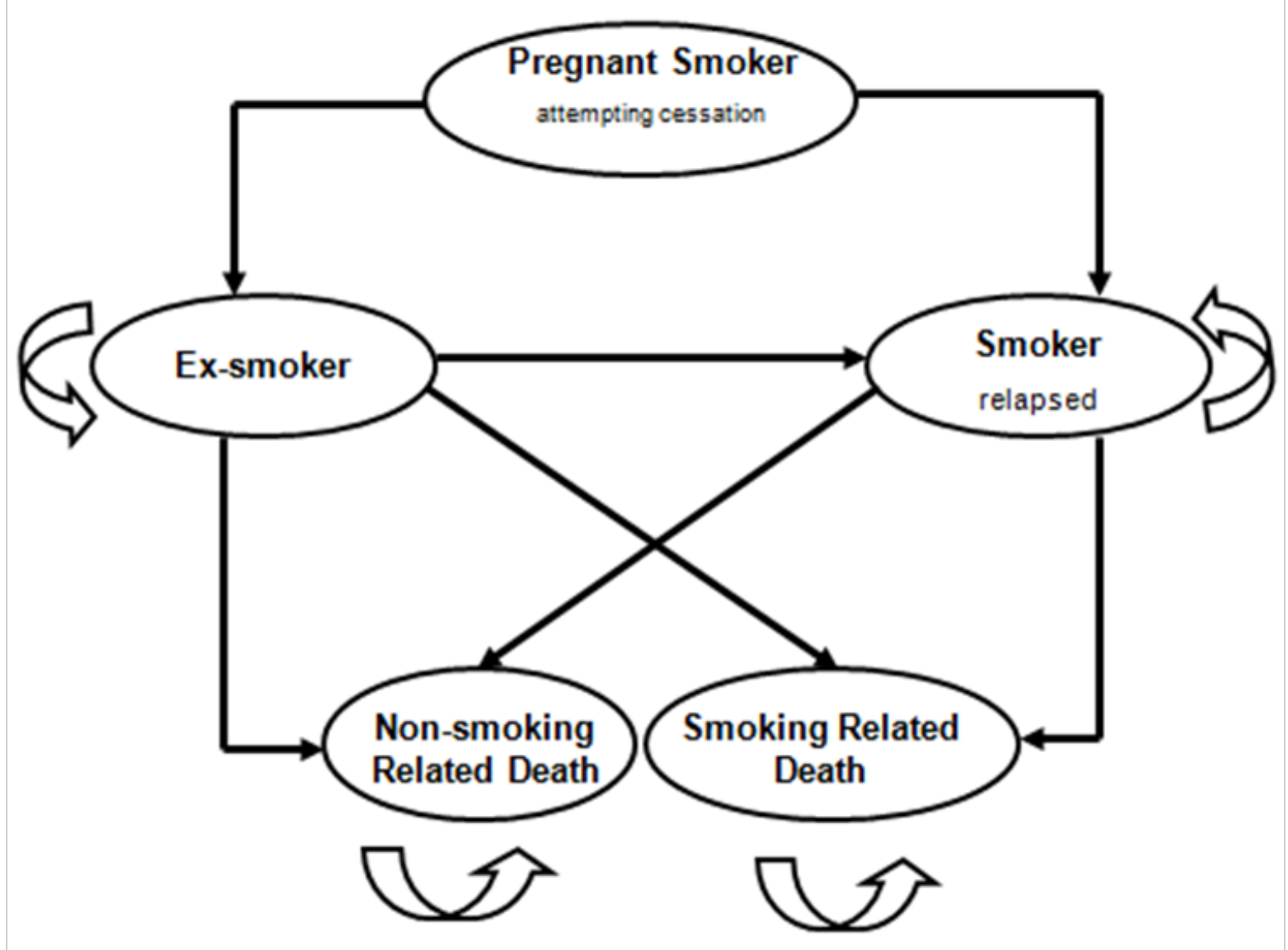

Figure 1: Markov Model 


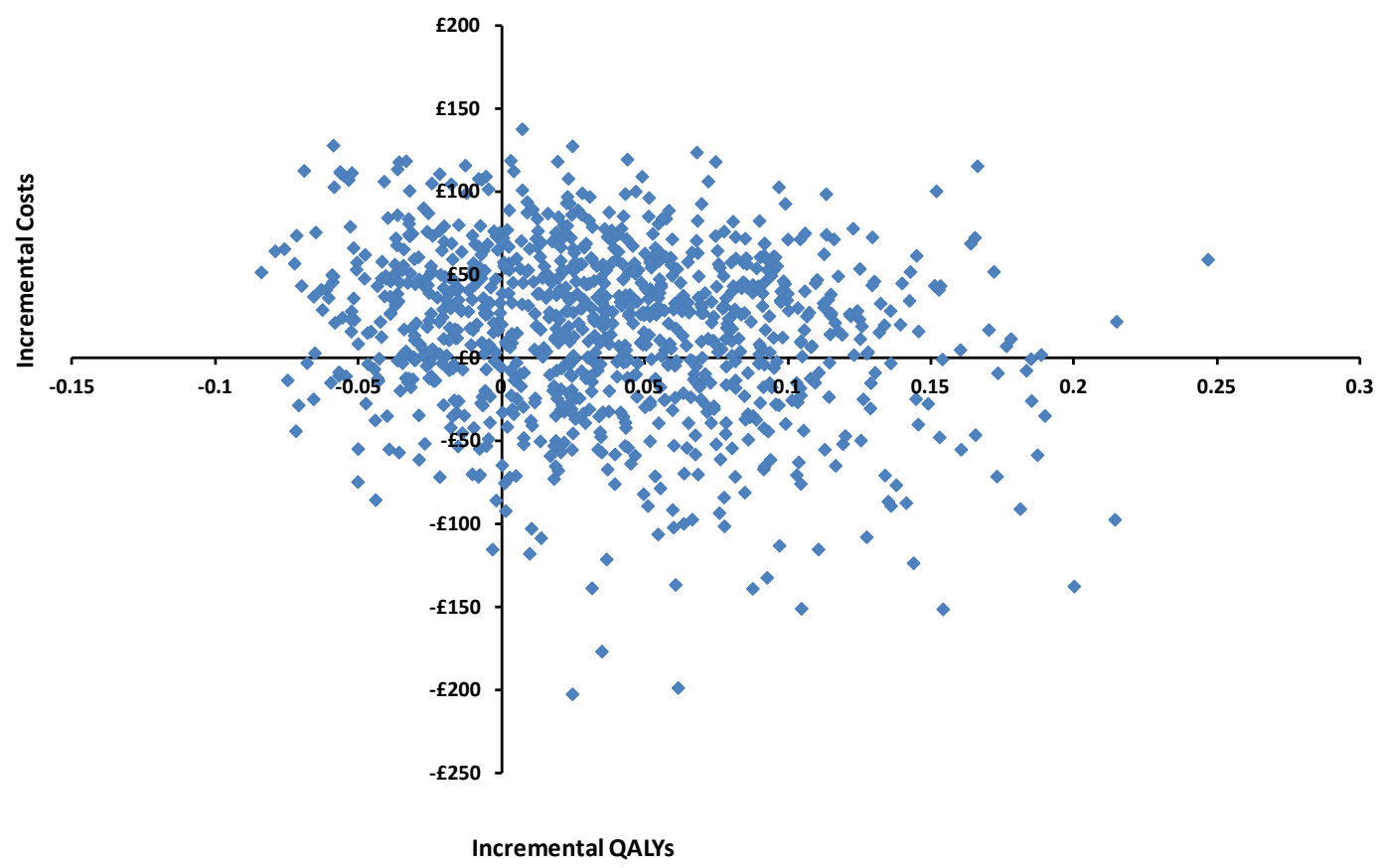

Figure 2: Cost-effectiveness plane - Financial Incentives versus Control

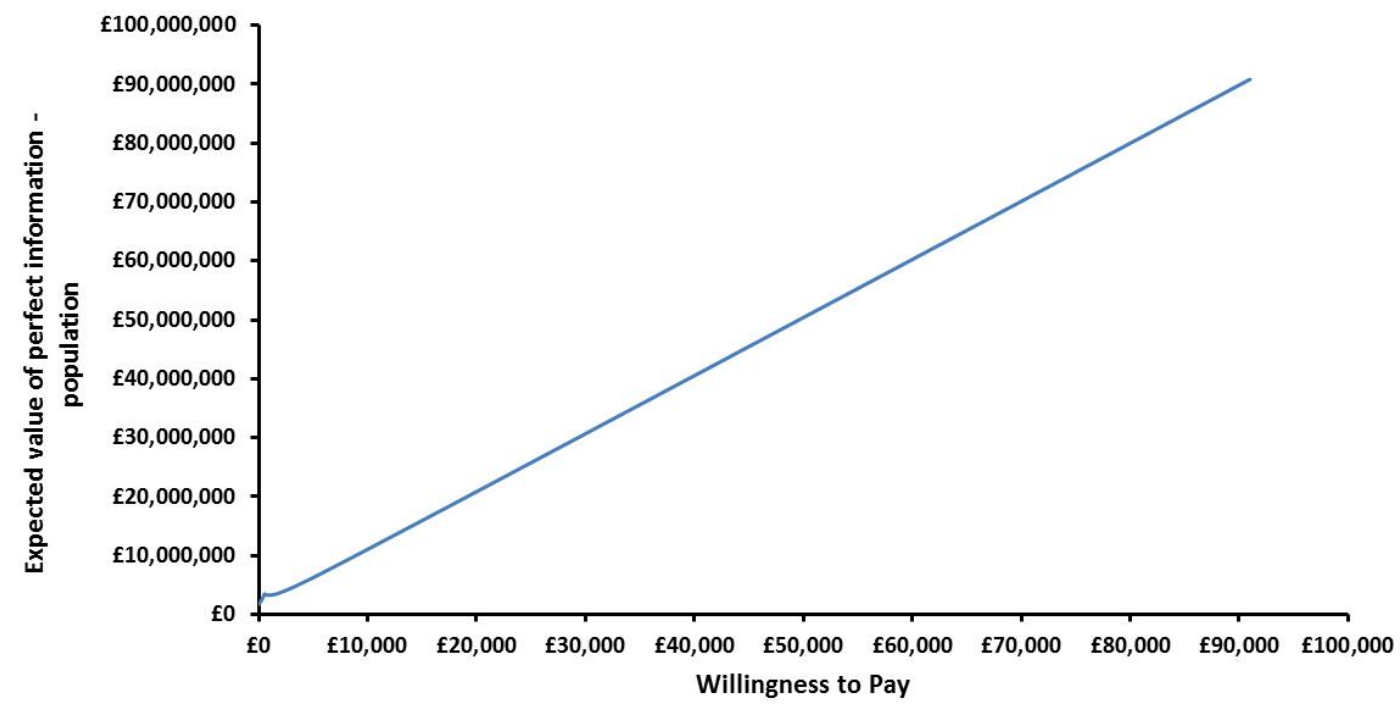

Figure 3: Expected Value of Perfect Information - population level 